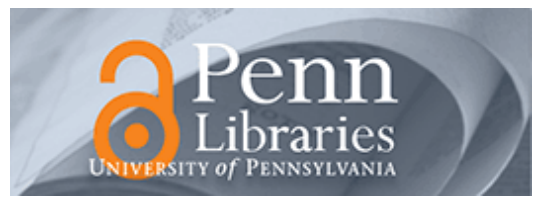

University of Pennsylvania

ScholarlyCommons

Management Papers

Wharton Faculty Research

$2-2010$

\title{
Should Auld Acquaintance Be Forgot? The Reverse Transfer of Knowledge through Mobility Ties
}

\author{
Rafael A. Corredoira \\ Lori Rosenkopf \\ University of Pennsylvania
}

Follow this and additional works at: https://repository.upenn.edu/mgmt_papers

Part of the Business Administration, Management, and Operations Commons, Business and Corporate Communications Commons, Business Intelligence Commons, Human Resources Management Commons, Management Information Systems Commons, Management Sciences and Quantitative Methods Commons, Organizational Behavior and Theory Commons, and the Strategic Management Policy Commons

\section{Recommended Citation}

Corredoira, R. A., \& Rosenkopf, L. (2010). Should Auld Acquaintance Be Forgot? The Reverse Transfer of Knowledge through Mobility Ties. Strategic Management Journal, 31 (2), 159-181. http://dx.doi.org/ $10.1002 /$ smj. 803

This paper is posted at ScholarlyCommons. https://repository.upenn.edu/mgmt_papers/326

For more information, please contact repository@pobox.upenn.edu. 


\title{
Should Auld Acquaintance Be Forgot? The Reverse Transfer of Knowledge through Mobility Ties
}

\author{
Abstract \\ While mobility's effect on knowledge transfer to firms that hire mobile employees is well demonstrated, \\ we choose to explore mobility's effect on knowledge transfer to firms that lose these employees. \\ Focusing on this 'outbound mobility' allows us to isolate effects of social mechanisms associated with \\ mobility. We find that semiconductor firms losing employees are more likely to subsequently cite patents \\ of firms hiring these employees, suggesting that mobility-driven knowledge flows are bidirectional. In \\ addition, the outbound mobility effect is pronounced when mobility occurs between geographically \\ distant firms, but attenuates for geographically proximate firms since other redundant knowledge \\ channels exist within regions.

\section{Keywords} \\ outbound mobility, knowledge transfer, localization, social capital, interfirm networks, semiconductor \\ industry

\section{Disciplines} \\ Business Administration, Management, and Operations | Business and Corporate Communications | \\ Business Intelligence | Human Resources Management | Management Information Systems | \\ Management Sciences and Quantitative Methods | Organizational Behavior and Theory | Strategic \\ Management Policy
}




\title{
Learning from Those Who Left: The Reverse Transfer of Knowledge through Mobility Ties
}

\author{
Rafael A. Corredoira \\ Department of Management, The Wharton School, University of Pennsylvania, Philadelphia, PA 19104, \\ corredoi@wharton.upenn.edu \\ Lori Rosenkopf \\ Department of Management, The Wharton School, University of Pennsylvania, Philadelphia, PA 19104, \\ rosenkopf@wharton.upenn.edu
}

May 1, 2006

Both authors contributed equally and are listed alphabetically. The authors thank Paul Allison, Mary Benner, Mauro Guillen, David Hsu, John Kimberly, Dennis Yao, and participants at the Applied Economics Doctoral Seminar at Wharton and at the Smith Entrepreneurship Research Conference for their comments on early versions of this paper, Paul Almeida for providing us with ICI and Dataquest alliance data, Hammad Iqbal, Alexander Mittal and Megha Narayan for help in data collection, and the Mack Center for Technological Innovation at the Wharton School for financial support. They also acknowledge use of the NUS Patent Database.

\section{PRELIMINARY -- Work-In-Progress}

Please do not cite without consulting authors 


\begin{abstract}
A host of studies have demonstrated that the mobility of technical employees among firms is associated with some transfer of knowledge from their previous firms to their new employers. To separate the human and social capital mechanisms in this process, we distinguish the "inbound mobility" generated by hiring from the "outbound mobility" generated by an employee leaving a firm. In contrast to most studies on mobility's effect on knowledge transfer, we focus on whether outbound mobility, rather than hiring, is associated with knowledge transfer to firms losing employees. In this situation, the social capital approach would predict that the firm losing an employee would gain access to the new employer's knowledge, while the human capital approach would not.

We examine these phenomena in 154 semiconductor firms between 1980 and 1995 . Results demonstrate that a firm experiencing outbound mobility is more likely to cite the firm receiving the mobile employee even after controlling for alternative mechanisms for knowledge transfer, such as alliances. This effect is stronger for geographically distant firms, suggesting that the communication channels formed are more valuable when they provide access to distant, presumably non-redundant knowledge. These results demonstrate the validity of a social capital approach to knowledge transfer and call into question the conventional wisdom that losing employees means losing knowledge.
\end{abstract}

Key words: Outbound Mobility, Knowledge transfer, Localization, Social Capital 


\section{INTRODUCTION}

Research on the effects of interfirm mobility focuses on how the gain or loss of employees shapes various organizational outcomes, including survival rates, access to knowledge, and influence. A wellestablished perspective in this research holds that mobile employees are repositories of skills, routines and knowledge that they carry with them from their prior employer to their new employer. Such a perspective, rooted in notions of portable human capital, tends to find that hiring firms gain from importing these employees. Thus, hiring firms have been found to import product line strategies (Boeker 1997) and technical knowledge (Rosenkopf and Almeida 2003) in the semiconductor industry; to increase product innovation in the mutual fund industry (Rao and Drazin 2002); and to increase their influence in technical committee activity (Dokko and Rosenkopf 2006).

A straightforward corollary of this notion is that the loss of employees to other firms can have negative consequences for the firms losing these employees. For example, Phillips (2002) demonstrates that the movement of partners between Silicon Valley law firms leads not only to an increase of the likelihood of survival for the hiring firms, but also a corresponding decrease in the likelihood of survival for the firms that lost partners. Wezel and colleagues (2006) note similar hazards for Dutch accounting firms that lose employees, particularly when the employees move in groups to nearby firms. In these cases, it is clear that mobile employees are carrying resources attributable not only to human capital but also to their accumulated social capital in the form of client and within-firm relationships.

This paper departs from previous studies by exploiting a unique characteristic of social capital: the bi-directionality of social ties in the context of information transfer. An employee moving from one firm to another removes and transfers something from the firm she leaves to the firm she joins - as previous research has correctly theorized - but also generates a communication channel between both firms (i.e., her social contacts at the firm she left). We consider that these channels become part of the social capital of both firms involved in the mobility event. Of course, in a study of gains for the firm hiring the employee, it is challenging to discern whether the underlying knowledge transferred relates to human capital, social capital or a combination of both mechanisms. For this reason, we theorize about the 
impact of losing an employee on inter-firm transfer of knowledge, our way to isolate social capital mechanisms.

Thus, while both human capital and social capital arguments predict gains for firms receiving mobile employees, they generate opposing predictions when we consider firms losing mobile employees. Specifically, while the human capital argument predicts losses for the prior employer, the social capital mechanism predicts gains for the prior employer. This is because the communication channels established between firms $\mathrm{i}$ and $\mathrm{j}$ as a result of employee mobility are assumed to be bidirectional, while the transfer of human capital is assumed to be unidirectional. In this spirit, Agrawal and colleagues (2003) suggest that "enduring social relationships" between inventors who have moved to new regions and their prior colleagues increase the likelihood of knowledge spillovers to the original locations of the inventors.

The purpose of this paper is to test whether outbound mobility is associated with a subsequent transfer of information from the firm that hired the employee to the firm that lost the employee. Such a transfer is in the reverse direction from the transfer of knowledge that has been well-demonstrated to the hiring firm. We examine this relationship by systematically exploring linkages between firms while controlling for a host of alternative mechanisms that might also affect knowledge flows to firms experiencing outbound mobility of inventors. In other words, we aim to answer the questions of how and when a firm losing an employee may subsequently draw upon the knowledge of the firm hiring the employee.

Our empirical setting, semiconductor industry research and development, is particularly suited to explore these questions for four reasons. First, patent activity in the industry is pervasive, providing a thick trail of documentation of knowledge development. Second, the industry is well-recognized as a context where innovation rests on the R\&D capabilities of individuals and firms operating under uncertainty. Since a long tradition of research on the diffusion of innovations suggests social interactions and ties have strong effect on actors' decisions under conditions of uncertainty (Rogers 2003), mobility is likely to influence communication channels and monitoring behaviors, which influence knowledge flows. 
Third, firms in this industry are locally clustered across diverse geographic regions, enabling us to contrast the effects of mobility within and across regions. And finally, inventor mobility may be inferred from patent records, which facilitates the study of the impact of interfirm mobility among crucial employees with a proven record in the development of patentable inventions.

The rest of the paper is organized as follows: the next section discusses knowledge transfer between semiconductor firms and develops propositions about the effects of outbound mobility and geographic proximity on technological knowledge transfer. It is followed by a section describing the methodology, sample and variables. A section presenting and elaborating on the results precedes the concluding section where contributions and implications are discussed.

\section{THEORY}

In this paper, we focus on knowledge transfer across firm boundaries in the semiconductor industry. We conceptualize knowledge transfer as the process by which an organization is affected by the experience of other organizations (Argote et al. 2000). This process may result in changes in the knowledge stock or performance of the organization receiving the transfer of knowledge. Among the mechanisms accounting for knowledge transfer across organizations identified in the literature are strategic alliances, employee mobility, informal communications, patents, and scientific publications.

Previous research on knowledge transfer has distinguished between the transfers of technological or scientific knowledge (Allen 1977). Regarding the transfer of technological knowledge, Allen and colleagues (Allen 1977, 1970; Marquis and Allen 1966) have advanced the thesis that it is contained inside organizations and does not transfer across research centers in different firms, and that this manner differs from the transfers of scientific knowledge which diffuses across organizations freely. Their argument is based on the fact that organizations face a competitive environment and are profit seekers. This constrains and prohibits the emergence of social networks of the type of invisible colleges among researchers. On the other hand, Levin (1988) has found that in the case of high-tech industries (which according to his definition included the semiconductor industry) firms report conversations with employees of innovating firms as a relevant mechanism for learning from other firms. This is consistent 
with accounts of the importance of informal communications in Silicon Valley as a mechanism of knowledge transfer across organizations (Saxenian 1994; Rogers and Larsen 1984).

\subsection{Outbound Mobility and Knowledge Transfer}

In developing innovations firms learn from others, and this transfer of knowledge across firms' boundaries is a crucial part of the development process. While studies have demonstrated the effects of strategies and tactics like alliances and inbound mobility on knowledge access and transfer, the effects of outbound mobility for firms losing employees have not been explored systematically. There are two distinct mechanisms by which firms losing employees may obtain increased access to the knowledge of the new employer.

The first mechanism by which outbound mobility may generate knowledge flow is by the establishment of interpersonal communication channels between the firm hiring the employee and the old firm. In some sense, the term "establishment" is misleading here, as the interpersonal relationship between the employees already existed when they worked together at the prior employer; the tie between people endures. However, when firm-level networks are considered rather than individual-level networks, the mobile employee's arrival at the new firm establishes a link between the old employer and the new one. Despite the proprietary concerns that would theoretically arise with knowledge transmission after such a move, substantial anecdotal evidence supports that it does occur. Rogers and Larsen (1984, p. 82-3) note:

"In Silicon Valley an engineer may disclose technical information to a former colleague who now works for a competing firm... Information-exchange due to friendship was described... [by an executive at National Semiconductor in this way]...: 'We all know each other. It's an industry where everybody knows everybody because at one time or another everyone worked together. "”

Likewise, Fleming and colleagues (2004) note:

"He [research engineer] usually maintained links to these individuals [earlier research collaborators] by passing back old information relating to his prior work, rather than by applying that same information to his new work going forward."

And 
“...[Firm] XYZ did not, "give you time for any outside life [that would enable knowledge transfer]." Yet, before starting a project, he reported that XYZ engineers call their friends (who include colleagues at other firms), contact professors at universities, and read the patent and scientific literature."

Thus, professional allegiance and its norm of generalized reciprocity (Merton 1973; Price 1986) facilitate know-how trading (von Hippel 1987) among technical employees working at different firms. The social connections across firms' boundaries created by a mobility event - i.e., social ties that were developed between the mobile employee and fellow workers during her tenure in the firm she left - are likely to facilitate these sorts of knowledge flows.

The second mechanism by which outbound mobility may generate knowledge flows is by increasing the salience of the receiving firm as a producer of useful knowledge. Ocasio's (1997) attention-based view of the firm suggests that firm-level cognition is bounded and influenced by particular events. Ocasio identifies the patterns of interactions between members of the firm interactions that are forged by formal and informal structures over time - as playing a crucial role in the process of finding the solutions. The patterns of information search become routinized (Nelson and Winter 1982), and over time individuals are recognized as the source for particular types of information; which, in the case of research centers, means that inventors have proved themselves as sources of information leading to innovations.

In our case, when an employee leaves one firm for another, his/her colleagues remaining at the prior employer can become more aware of the new employer as a site where knowledge worth knowing is being produced. Such effects would be more pronounced when the new employer is a startup that has not yet become fully legitimized in the industry. By having one of their own going to that firm, work in the receiving firm gains credibility and saliency. The firm receiving the employee thus becomes more highly monitored for innovation opportunities. Through this monitoring process, the firm that has lost the employee may gain knowledge (which may have even been in the public domain, but not incorporated to its own knowledge reservoir). 
Whether the underlying mechanism is posited to be the establishment of a communication channel or increased salience and monitoring of the activities of the receiving firm, both mechanisms lead us to predict:

Hypothesis 1: $\quad$ Outbound Mobility increases the hazard of the firm losing the employee drawing on the knowledge of the firm hiring the employee.

It is important to note that the mechanisms described above are not limited to the case of outbound mobility but can also work in parallel with the transfer of skills and knowledge embedded in the employee for the hiring firm. What is unique about outbound mobility is that if an instance of transfer of knowledge to the focal firm from the alter is found associated with the event, absent an employee hired by the focal firm from the alter, the transfer of knowledge cannot be explained by the inflow of skills and knowledge embedded in any employee.

\subsection{Outbound Mobility, Geographic Proximity and Knowledge Transfer}

While our interest will be in how geographic proximity or distance affects the relationship between outbound mobility and knowledge transfer, we begin by reviewing the baseline effect of geographic proximity on knowledge transfer. The notion that knowledge spillovers are localized is wellestablished in the literature (cf. Hagerstrand 1967; Jaffe, Trajtenberg, and Henderson 1993; Almeida and Kogut 1997; DeCarolis and Deeds 1999; Agrawal 2001; Singh 2003). Although mobility is acknowledged as one of the key mechanisms by which knowledge spillovers occur within regions (Almeida and Kogut 1999), a host of informal contacts arise through the multitude of professional associations, casual gathering places, and other social contacts that arise between geographically proximate people (Saxenian 1994).

Hypothesis 2a: Geographic proximity between the focal and alter firms increases the hazard of the focal firm drawing on the knowledge of the alter.

According to Tang and Inkpen's (2005) characterization of the industrial district, social networks are what support localized knowledge spillovers. Inventors who are part of a social network generated by mobility ties develop a shared culture and trust - originated in the shared socialization process scientists 
are exposed to during their training years in universities and technological centers (DiMaggio and Powell 1983) and the years working together for the same firm. Thus, we expect that the access to information obtained through an outbound mobility tie is likely to be available through other mechanisms when the tie is contained inside an industrial district, but not when mobility occurs across industrial districts' boundaries. Rosenkopf and Almeida (2003) reach a similar conclusion -- knowledge transfer effects of hiring within may be less pronounced than of hiring across geographic regions - based on traditional sociological arguments that bridges to new contexts provide the most valuable knowledge (Granovetter 1985; Burt 1992).

Therefore, we conclude that in our context, this means that an outbound mobility event within a geographic region is more likely to create a duplicative channel for the transfer of knowledge due to the multiplicity of channels already available within a region. In contrast, an outbound mobility event to a distant region is more likely to create a unique channel by which useful (i.e., non-redundant) knowledge can flow. As a result of this redundancy, we propose:

Hypothesis 2b: Geographic Proximity decreases the effect of Outbound Mobility on the hazard of the focal firm drawing on the knowledge of the alter firm hiring the employee.

\section{METHODOLOGY}

\subsection{Data and Variables}

Data was collected in the context of the semiconductor industry. In order to collect the different variables, the information on the front page of the patents granted by the USPTO, obtained from National Bureau of Economic Research (NBER) U.S Patents (Hall, Jaffe, and Tratjenberg 2001) and National University of Singapore Patent databases, was utilized together with data from ICE, Dataquest and SDC Platinum databases.

Among all the types of knowledge transferred, scientific and technological knowledge leaves a trace on paper when that knowledge is granted a patent. Patent legislation in the U.S. requires the inclusion of the following elements in the patent: the knowledge patented (which has to be original and 
innovative), the owner of the patent, the inventors and their geographic location, and citations to all the relevant patents that this new invention has built on. Therefore, and because an officer of the patent office controls the appropriateness and comprehensiveness of the citations, a patent becomes a physical record of the transfer of knowledge to the firm (represented by each instance of a citation of another patent) (Jaffe, Trajtenberg, and Henderson 1993; Almeida and Kogut 1999). As discussed by Jaffe et al (1993), this is not to say that patents are able to capture all instances of knowledge transfer between firms (knowledge transferred may result in no patent granted) or that every citation is an instance of knowledge transfer (the citation could have been included by the patent officer). ${ }^{1}$ Despite these limitations, patents are generally acknowledged as sources of information transfer in the US (Cohen, Nelson, and Walsh 2000; Cohen et al. 2002) and patent citations are records that allow us to track when a firm draws on other firm's knowledge stock - as per our definition, a case of knowledge transfer. In addition, the concern about a firm acting on knowledge transferred without resulting in a patent is partially lessened by the fact that the semiconductor industry relies on patenting as a mechanism to protect firms' ability to profit from their intellectual capital. Thus, the patent process is standardized and requires the inclusion of information about location of the inventor and the firm (which allows tracking of mobility and geographic location) and citation of previous patents from where the innovation draws (a process refereed by patent examiners that control the adequacy and completeness of the citations) (Jaffe, Trajtenberg, and Henderson 1993).

\subsubsection{Sample.}

All the firms that between 1980 and 1994 have at least one US semiconductor patent, as per NBER classification: main classes $257,326,438$, and 505, are included in the sample. This results in a

\footnotetext{
${ }^{1}$ Nevertheless, a citation, despite being included by the patent officer, can still be an actual record of knowledge transfer of which the grantee is unaware (a case of cryptomnesia (Jung and Franz 1968; Merton 1973)) or unwilling to disclose. Even in the case that the inclusion does not represent an actual record of knowledge transfer, we cannot see a reason why this mandatory addition by the officer is correlated in any form to the mobility event. Thus, this may introduce noise to our measure but does not bias the results in the direction predicted in this paper.
} 
total of 154 firms. All the patents granted to those firms that have application dates between 1975 and 1995 were gathered from the NBER database. This results in a dataset of around 42,000 patents. Information for all firms that designed or manufactured semiconductor devices was obtained from databases compiled by ICE and Dataquest, two private research firms specializing in semiconductor industry analysis, for the period 1980-1989, and from SDC Platinum for the period 1990-1995.

\subsubsection{Variables.}

The unit of analysis for these variables is the dyad - the firm citing (focal firm) and the one being cited (alter firm). The dependent variable was measured for each dyad-year for the period 1985-1995. In other words, our dataset contains one observation for each dyad in the sample for each year of observation. All the independent variables preceded in time the dependent variable (count of citations). Due to the time lags introduced in the patenting process, several of our independent variables are measured over multi-year windows as we describe below.

Citation Count (Cites). For each dyad (focal and alter firms), this variable is a count of the number of times the focal firm cited the alter on patents granted with application date on the year of observation. Each citation is treated as one instance of the focal firm's drawing upon the knowledge of the cited firm. Cites is compiled from the NBER dataset.

Outbound Mobility (OutMob). This variable identifies the instances when an inventor moved from a focal firm to a alter firm in our sample. According to our previous discussion, mobility provides a channel for new information to reach the firm. The firm has to act on this new information and create an innovation to be patented. Jaffe and colleagues (1993) reported that patent citations reach a peak between 3 to 5 years after the patent was granted. However, the pattern of citations clearly indicates that there is not an exact lag between access to information and the generation of a patent drawing on that information. In addition, studies on the effect of mobility and alliances have found that mobility of inventors during the 80s has an effect on citation patterns for the period 1990-1995 (Almeida, Dokko, and Rosenkopf 2003; Rosenkopf and Almeida 2003). For these reasons, we selected a 5-year window to measure the different types of mobility and alliances. 
We examined the set of semiconductor patents for each firm in our sample between the years 1980 and 1995 in order to find mobility events. Each inventor listed on the semiconductor patents through the 1980-1995 period was then tracked, looking for instances where inventors were employed by more than one firm over their patent trajectory. A case of mobility was identified when a researcher is listed as inventor in patents granted to two different firms. ${ }^{2}$ Since with this procedure it is impossible to pinpoint the exact date of mobility, we use the following approach: the time of the mobility event is the application year of the first alter's patent where the mobile employee appears as inventor. This approach eliminates the possibility that we could identify mobility as occurring before it actually did. We coded Outbound Mobility as 1 if at least one case of outbound mobility has occurred in the 5-year window preceding the year of observation, otherwise it is coded as 0 .

Geographic proximity (GeoProx). When two firms are located in the same Metropolitan Statistical Area (MSA) or same country (in the cases of foreign firms) geographic proximity is coded as 1 , otherwise it is coded as 0 . This variable indicates how proximate two firms are and, as such, how easy the transfer of information between them is. We utilized the MSA for 1993 as defined by the US Office of Management and Budget (6/30/1993) (See Table 1 for MSA codes and names). The location of the firm was obtained from the first page of the USPTO patents granted to the firm during the year of the observation. For firms reporting more than one location across their patent portfolios, we assumed the primary location to be the site with the majority of the patents ${ }^{3}$.

\footnotetext{
${ }^{2}$ By this procedure we are able to identify only those mobility cases of researchers that appeared as inventors in patents granted to both firms. A mobility event is not detected when a researcher moves from one firm to another without being listed as an inventor in any patent of any of the firms. Despite only tracking researchers listed as inventors, the results of this study are relevant because we are capturing the mobility of researchers with higher human capital (being acknowledged as an inventor is a clear indicator of the high human capital of the researcher). As described above, we would expect a negative impact on the firm losing this kind of employee.

${ }^{3}$ Of the 154 firms 76 have presence in multiple regions. The average number of patents accounted for in the primary location, based on first inventor's address, is $89 \%$ with a median of $99.9 \%$. The first inventor's address is located in
} 


\subsubsection{Controlling for Alternative Mechanisms of Knowledge Transfer}

In order to increase the confidence on the results for outbound mobility of this study, we also considered the following alternative mechanisms of knowledge transfer.

Strategic Alliances. Organizations reach knowledge across firm boundaries by means of strategic alliances. In this mode, organizations create a structure that allows the participating firms to access each other knowledge or to develop common knowledge (Inkpen and Tsang 2005). Extant research has shown that firms that engage in strategic alliances (technically or marketing motivated) experience a transfer of knowledge across their boundaries (Almeida, Song, and Grant 2002; Rosenkopf and Almeida 2003; Song, Almeida, and Wu 2003; Almeida, Dokko, and Rosenkopf 2003; Stuart 2000). Therefore, we use Alliances (a dichotomous variable) to control for this expected positive effect. We obtained the alliances between each dyad of firms from databases compiled by ICE and Dataquest, for the period 1980-1989, and from SDC Platinum for the period 1990-1995. We coded this variable 1 when at least one alliance (either technological or marketing) is found in the 5-year window previous to the year of observation.

Hiring of employees. Organizations also access other firms' knowledge by hiring away each other's employees. Although it is common practice to have employees signing confidentiality agreements, what is learned in one place travels with the employee over time. And, without necessarily infringing the confidentiality agreement, employees are able to build around the knowledge they gained in their previous jobs, which is even easier when that knowledge is publicly available in the form of a patent. Empirical studies have shown that firms, when hiring away employees from other firms, access the knowledge of those firms that lost the employee (Bui-Eve 1997; Dokko and Rosenkopf 2006; Song, Almeida, and $\mathrm{Wu} 2003$ ). For this reason, we included a control variable showing hiring of employees, which we expect to have a positive effect on knowledge transfer across firms' boundaries. ${ }^{4}$

the primary location for at least $60 \%$ of the patents in $90 \%$ of the firms. For firms with presence in multiple regions, the average number of patents accounted for in the primary location is $80 \%$ with a median of $83 \%$.

${ }^{4}$ By including this variable, we have effectively decomposed employee mobility into two types of ties: hiring and outbound mobility. Although each mobility event generates one tie in each network, the networks are not identical 
To control for this mechanism, we utilize Hiring (a dichotomous variable) that captures the existence of the move of at least one inventor from the alter firm to the focal firm during the 5-year window before the year of observation. A parallel reasoning leads to the recording of hiring events in a similar manner to the recording of outbound mobility events; the time of the hiring event is the year of the application of the first patent of the focal firm on which the employee appears as inventor.

Absorptive Capacity. According to the absorptive capacity view, firms are more likely to learn from others the more knowledge they have and the closer this knowledge is to the source of information (Cohen and Levinthal 1990). Two variables are used to control for both dyad-specific and firm-specific characteristics of this type. Following Rosenkopf and Almeida (2003), Technological Distance (TechDist) reflects the dyad's common patenting patterns. For each patent with application date on the 10-year window previous to the year of observation, we tabulated to which technological class/subclass (main class/subclass) it was assigned and created a vector with the percentage of patents assigned to each class/subclass for each firm. Then, we calculated the TechDist between two firms as the Euclidean distance between the vectors just described. ${ }^{5}$ Smaller values indicate technologically proximate firms, and TechDist is expected to be negatively associated with our dependent variable.

Focal firm's number of patents (FocPat5) represents the firm's stock of knowledge. It is the count of patents granted to the firm that have application dates in the 5-year window previous to the year

because the ties have directionality. This means that, by definition, a focal firm's outbound mobility ties can be uncorrelated with its hiring ties. For example, if John left firm ABC to go to firm XYZ, we record an outbound mobility tie for $\mathrm{ABC}$ (focal) to XYZ (alter) and a hiring tie for XYZ(focal) from ABC (alter). Absent an employee moving from $\mathrm{XYZ}$ to $\mathrm{ABC}$, we do not have a hiring tie for $\mathrm{ABC}$ (focal) from $\mathrm{XYZ}$ (alter).

${ }^{5}$ Other researchers have utilized measures of technological distance based on citation patterns (Stuart and Podolny 1996; Mowery, Oxley, and Silverman 1998); however, using this patent class derived measure of technological similarity follows in a long tradition of studies initiated by Jaffe (1989; Jaffe 1986) and pursued by several scholars in economics and strategy since. It also allows us to keep the technological similarity and knowledge flow variables conceptually and empirically separate. 
of observation. We utilized 5-year windows to count the number of patents as a proxy for firms' knowledge stock because we consider that a patent's value has depreciated after that period of time. Larger values of this variable are expected to be associated to a larger stock of knowledge for the focal firm. We utilized the natural log of this variable because it is heavily skewed.

In addition to these variables we also included the following controls:

Alter firm's number of patents (AltPat10). This variable measures the number of patents granted to the alter of the dyad during the 10-year window previous to the year of observation. In the case of the number of patents at risk of being cited, we utilized the 10-year window, which, according to Jaffe and colleagues' finding, is the time it takes a patent to start receiving a negligible number of citations per year In this way we control for the increase in the probability of citing another firms resulting just from the sheer number of patents. We utilized the natural log of this variable because it is heavily skewed.

Focal firm's number of patents on year of observation (FocPat) is the count of patents granted to the firm that have application dates during the year of observation. In this way we control for the increase in the probability of citing existing patents just from the sheer number. We utilized the natural log of this variable because it is heavily skewed.

Year86-Year95. These are ten dummy variables to control for unobserved effects associated with each year of observation.

\subsubsection{Data Description}

In total, the dataset contains 140,614 observations, one per each combination focal firm-alter firm-year for which all the variables can be measured. Table 1 displays the geographic distribution of our firms across 23 MSAs in the United States and 11 foreign countries, which comprise our 34 regions. Several regions appear to be well-populated with firms in our sample. Indeed, the four regions with 7 or more firms (Silicon Valley, Japan, New York, and Los Angeles) contain approximately two-thirds of the firm population, which suggests geographic clustering. At the same time, sixteen regions (four countries and 12 MSAs) contain only one firm, which cannot, by our construction, experience intra-regional 
mobility. Furthermore, three firms in the United States are in three locations that do not belong to any MSA and, for this reason, they are not assigned to any region.

During the period from 1980 to 1994, 450 cases of mobility and 610 alliances between firms were identified. Figure 1 displays the yearly number of events of each type. Clearly the levels of both mobility and alliances trend upward; however, alliances appear to have peaked while mobility appears to be still growing. As described above, these events were used to generate the observations for OutMob, Hiring and Alliances; given our five-year windows, the number of observations exceeds the number of actual events.

Thus, Table 2 tabulates the number of observations of OutMob, Hiring and Alliances by geographic proximity (Table 2a) and then subdivides these tabulations for key regions in our sample (Table $2 b$ ). Table $2 \mathrm{a}$ tests for the localization of mobility and alliances via $\chi 2$-tests. Clearly, mobility within regions occurs more frequently than would be expected given the distribution of firms across regions. In contrast, alliances actually occur within and across regions proportionally to the distribution of alliance opportunities within and across regions ${ }^{6}$.

Table $2 \mathrm{~b}$ examines how the distribution of cases of $O u t M o b$ within and across regions varies by the region of the focal firm. Two regions in our sample - Silicon Valley and Japan - lose more employees to other firms in the same region than firms outside their regions. Furthermore, these regions account for most of the mobility within, but not across, regions. Focal firms located in Silicon Valley (MSA code $=7362)$ are responsible for $33 \%$ of the same-region $($ GeoProx $=1)$ and $12 \%$ of the acrossregion (GeoProx = 0) OutMob cases, while Japan is responsible for 54\% and 10\%, respectively. Similar patterns are found in the dataset for hiring and alliances. Another interesting fact is that Silicon Valley is the MSA accounting for the largest number of hiring from different regions (175 observations out of 683) and the second largest number of employees leaving one region (81 observations out of 683 ). This

\footnotetext{
${ }^{6}$ Results from Mantel-Haenzel tests (Mantel and Haenszel 1959) show a significant, positive association between geographic proximity and $\mathrm{OutMob}$ and Hiring even after controlling for the region where the focal firm is located (results available from the authors).
} 
provides some evidence that Silicon Valley is acting as a hub of technological knowledge. Full descriptive statistics are presented in Table 3.

\subsection{Model}

Our dependent variable is a count of the number of citations the alter firm receives from the focal firm over the year of observation. Since our dataset includes repeated observations for each focal firm (for different alters and years), it violates the assumption of independence across observations. In addition, an estimation of a Poisson model indicates that the dataset suffers from overdispersion and excess zeros (the standard deviation is larger than the mean and the number of non zeros for the dependent variable is less than $12 \%$ of the total number of observations, see Table 4). For these reasons, we estimate a zero inflated negative binomial regression (which corrects for overdispersion and excess zeros) with fixed effects on the focal firm (which corrects for the interdependence between observations of the same focal firm) utilizing SAS v. 9.1.

\subsubsection{Model Specification.}

We propose a mixed model where count of citations is predicted by a negative binomial model, which is simultaneously estimated with the inflation model utilizing maximum likelihood (Cameron and Trivedi 1998). The inflation model predicts zeros by the number of patents of the alter during the previous 10 years, the number of patents of the focal firm with application date during the year of observation and the technological distance between the firms. To summarize, this logistic model predicts no citation based on how many patents are available to be cited, how many patents have a chance to cite those available for citation, and the proximity of both firms' technology.

Therefore, the inflation model has the form:

$\log \left(1 / 1-\pi_{\mathrm{ijt}}\right)=\mathrm{b}_{0 p r}+\beta_{p r} \mathrm{X}_{p r}+\alpha_{p r_{-} \mathrm{i}}$

where $\pi_{\mathrm{ijt}}$ is the probability of Cites $_{\mathrm{ijt}}>0, \mathrm{X}_{p r}$ is a vector of the variables predicting the occurrence of no-citation, $\beta_{p r}$ is a vectors of coefficients to be estimated, $\alpha_{p r_{-} \mathrm{i}}$ is the term that captures the fixed effect of focal firm $(i)$, and $i, j$, and $t$ indicates the observation correspond to the focal firm $(i)$, the alter firm $(j)$ on year $(t)$. The negative binomial model has the form: 
$\mathrm{g}\left(\right.$ Cites $\left._{\mathrm{ijt}}\right)=\mathrm{b}_{0}+\beta \mathrm{X}_{\mathrm{ijt}}+\gamma \mathrm{Y}_{\mathrm{ijt}}+\delta Z_{\mathrm{t}}+\varphi_{\mathrm{t}}+\alpha_{\mathrm{i}}+\varepsilon_{\mathrm{ijt}}$

where $\mathrm{X}$ is a vector of dyadic variables that test our hypotheses; $\mathrm{Y}$ is a vector of dyadic control variables; $Z$ is a vector of firm control variables associated to the focal $(i)$ and alter $(j)$ firms; $\beta, \gamma$ and $\delta$ are vectors of coefficients to be estimated; $\varphi_{\mathrm{t}}$ is a vector capturing year $(t)$ effects; $\alpha_{\mathrm{i}}$ is the term that captures the fixed effect of focal firm $(i) ; \varepsilon$ is the error term with a log-gamma distribution; and $i, j$, and $t$ indicates the observation correspond to the focal firm $(i)$, the alter firm $(j)$ on year $(t)$.

The fixed effect estimation controls unobserved heterogeneity, corrects spuriousness, and reduces endogeneity concerns (Allison 1999). The correlations between the independent variables are low (see table 3) and VIF and tolerance tests (SAS v.9.1) show that the data do not have multicollinearity problems.

We ran a series of nested models in which we added variables consecutively. The base model (Model A) included the year effects (to capture unobserved differences across the period 1986 to 1995), $\log ($ AltPat10), TechDist, $\log$ (FocPat5), Alliance, and Hiring. Then, four other models were estimated by consecutively adding OutMob (Model B), GeoProx (Model C), OutMob and GeoProx together (Model D), and OutMob*GeoProx (Model E). Log Likelihood Ratio tests ${ }^{7}$ show that each variable addition to a model (full model) results in significant model fitting improvements over the model without the variable (reduced model), with $p$-values smaller than 0.05 , see Table 5.

\section{RESULTS}

In order to confirm that our mixed model conforms to our expectations about the impact of the control variables on citation patterns we look at the coefficients of those variables. First, inflation models show that all the variables behave as expected with coefficients significant at the 0.01 level. As expected,

7 The Likelihood Ratio test statistic -- ABS(2logLmodelA-2logLmodelB) -- has approximately a $\chi 2$ distribution with d.f. equal to the difference in the number of parameters between reduced and full models. The null hypothesis of this test is that the reduced model is equivalent to the full model. 
the positive sign for the TechDist coefficient indicates that the probability of no citation increases when firms are more distant, while the negative coefficients for the number of patents owned by the focal firm and the alter firm indicate than the probability of zero citation decreases the more patents were granted to the alter firm in the last 10 years and the larger the number of patents applied by the focal firm in the year of observation.

Second, a look at the coefficients for the control variables in the different negative binomial models shows that, in general, they behave as expected. In the case of the dummy variables capturing unobserved differences across years, there are only significant differences between the baseline (year 1985 ) and the years $1988,1989,1990,1991$, and 1995. As predicted by the absorptive capacity perspective, the focal firm's number of patents (FocPat5) is significant at 0.01 level and positive in all models. TechDist, however, is not significant. Therefore, the mixed model suggests that while technological distance increases the probability of zero citation, it has no influence on the number of times a focal firm cites an alter. Congruent with our expectations, the effect of alliances is also positive and significant at 0.01 level. An unexpected result is found for Hiring, which loses significance once GeoProx is added to the model.

In order to confirm that our mixed models support our hypotheses about the impact of outbound mobility and geographic proximity on citation patterns we look at the coefficients of those variables. An examination of our independent variables generally supports our hypotheses. The effect of outbound mobility on citation is significantly positive in model B, but only marginally significant when proximity is included in the model. Clearly, the effect of geographic proximity demonstrates geographic localization of citations, supporting Hypothesis 2a. When we include the interaction of outbound mobility and proximity, however, we find that the effect of outbound mobility across regions is indeed positive and significant (beta $($ OutMob $)=.198, p$-value $<.01)$, while the effect of outbound mobility within regions is not significant (beta $\left(\right.$ OutMob) + beta $\left(O u t M o b^{*}\right.$ GeoProx $)=.198-.306=-.108$, ns $)$ We find support for Hypothesis $2 b$, since geographic proximity decreases the effect of outbound mobility on citation. 
The inclusion of geographic proximity in the models dramatically influences the observed effects of the different mechanisms. It is interesting to note that when ignoring the localization of knowledge, the effect of alliance, hire and outbound mobility on the citation hazard are similar $-13.4 \%$

$(100 *\{\exp (.126)-1\}), 11.5 \%(100 *\{\exp (.109)-1\})$, and $17.7 \%(100 *\{\exp (.163)-1\})$, respectively - with no significant difference between the coefficients. On the other hand, with the inclusion of geographic proximity (accounting for an increase of the citation hazard between 35.7\% and 39.2\%), the increase due to alliance remains at $15.0 \%(100 *\{\exp (.140)-1\})$ while the effects of hiring and outbound mobility are dramatically attentauted in magnitude and significance. It is the introduction of the interaction term between geographic proximity and outbound mobility that makes evident the outbound mobility main effect, an increase in the hazard of $21.9 \%(100 *\{\exp (.198)-1\})$, and an interaction term that results in no effect when outbound mobility occurs in the same region.

A plausible explanation for the attenuation of the Hiring and OutMob effects when GeoProx is introduced is that different networks of personal ties are more likely to be located inside an industrial district (i.e., networks generated by the mobility of non-inventor employees, golf links, or neighborhood), and those personal ties might be the mechanism utilized to reach inventors in other firms. Since mobility of employees tends to involve geographically proximate firms, in model A, Hiring and OutMob may be capturing the effect of all the mechanisms of knowledge transfer associated with geographic proximity. When GeoProx is included in models C to E, Hiring and OutMob only capture the effect of inventor mobility while the rest of the mechanisms are captured by GeoProx.

\section{DISCUSSION}

In this study, we have challenged the prevailing conception of mobility as an event that creates a unidirectional flow of information from the previous employer to the new employer. Focusing on sociological explanations in a network of firms tied by mobile inventors, we suggest that mobility creates a bidirectional flow of information between the firms. With this distinction in mind, the results advance our understanding of knowledge flows; providing a more complete picture of the processes involved in knowledge transfer while offering empirical evidence that suggests an important role for social capital in 
facilitating inter-organizational flows Our results show that organizations receive knowledge by mechanisms that operate at organizational, individual and regional levels. Mechanisms based on organizational structures (alliances), acquisition of human capital (hiring) and acquisition of social capital (outbound mobility), social networks contained in a geographic region (geographic proximity), and absorptive capacity (stock of knowledge, technological distance) all facilitate the transfer of technological knowledge across firms in the semiconductor industry.

While some of our results replicate the well-accepted findings on geographic localization of knowledge due to mobility, we diverge from this common path by demonstrating that the effect of outbound mobility on citation is actually stronger when the mobility occurs across regions. Such an approach - recognizing the value of connections to distant, non-redundant sources of information - is consonant with the general view espoused by Rosenkopf and Almeida (2003) of the effects of both hiring and alliances over both geographic and technological landscapes, as well as the specific view of Agrawal and colleagues (2003) on how knowledge spillovers across regions are promoted by enduring social relationships between individuals. To reiterate, mobility across regions creates non-redundant network connections that seem to facilitate the flow of knowledge across firm boundaries. Future research must continue to explore the dynamics of the network connections established via mobility, and to discern both the social and human capital mechanisms inherent in these mobility ties.

Overall, the results support our hypotheses, even after controlling for other mechanisms of knowledge transfer. When outbound mobility involves the moving of employees between regions, the overall effect is positive. However, the similar size of the coefficients for OutMob and the interaction OutMob*GeoProx suggests that the effect disappears when the mobility event occurs inside a MSA or in a foreign country. This would indicate that outbound mobility is a redundant mechanism in a contained region or industrial district, which, as per Inkpen and Tsang's description (2005), involve many mechanisms of knowledge transfer that would provide similar access to knowledge. One would expect geographic proximity to be enough to facilitate the access to inventors in other firms. Attendance to 
meetings and common places, shared customers or suppliers, or shared acquaintances would provide these channels without the need of a personal tie created by working together previously.

An interesting puzzle in our results is that the effect of outbound mobility seems to be more robust and, although not significantly different, it is in general slightly larger than that of hiring. At one level, this is surprising, as outbound mobility can only rely on the social tie as a mechanism for knowledge transfer, while hiring implies the transfer of knowledge with the employee in addition to the social tie. We believe that this is a fruitful area for future research to understand how human capital and social ties mechanisms combine to facilitate knowledge transfer. In an attempt to reconcile this empirical finding with our theory and results, two possibilities come to mind: this empirical detail may result from 1) the influence of non-compete and non-disclosure arrangements that are so common in high-tech industries, and 2) the hiring firm being more likely to be aware about the knowledge of the firm losing the employee before the mobility event.

It is important to reconcile our finding, that outbound employee mobility benefits the firm losing the employee, with recent findings by Phillips (2002) and Wezel and colleagues (2006), who suggest that losing employees means a loss for the firm. We believe that this conflict is generated because the studies address different phenomena. While all of these studies focus on the transfer of capabilities, our study focuses on the transfer of knowledge as measured via patents, while the other studies may rely heavily on the transfer of clients and its implications for economic performance. Client relationships, repeated economic transactions by their very nature, are likely to move to the new employer and be severed at the previous employer, generating significant economic penalties for firms that lose employees and their clients. In contrast, knowledge generation relies on a more unique combination of inputs, may be utilized at both employers. As our interest is in knowledge flows among firms, we find that access to, and assimilation of, knowledge is enhanced when employees move to new firms. While we suggest that the firm losing the employee increases the utilization of the body of knowledge of the firm receiving the employee, our study is not designed to address the economic implications of this activity. 
That technological knowledge transfer is mainly contained inside the region may have found support in the previous literature by only looking at firms located in one region, or by ignoring the interaction between outbound mobility and geographic proximity. When this interaction is taken into account, our model shows that the transfer of technological knowledge follows a mechanism similar to scientific knowledge. At the end of the day, whether technological knowledge is able to flow across organizational boundaries or firms are able to contain it is a matter of empirical verification. Our results support the position that despite organizations' efforts to contain this flow (Rogers and Larsen 1984), knowledge appears to flow across organizational boundaries in ways that involve strategic moves (alliances and hiring) or non strategic ones (losing employees). It appears that even technological knowledge spreads in a manner that is similar to scientific knowledge, at least when this knowledge is made public in patents. This is consonant with Levin's (1988) findings, in particular in the setting of the semiconductor industry, where informal conversations with employees of other firms rank high in the mechanisms of learning. Outbound mobility facilitates access to those employees, and becomes particularly important when this access is not available.

A look at the structure of our data illuminates limitations and opens new questions. The particular characteristics of Silicon Valley are well-documented, with one of the highest rates of mobility and abundance of social interaction between employees of different firms (Rogers and Larsen 1984; Saxenian 1994). Our results regarding the interaction between geographic proximity and outbound mobility may have been driven by these facts, since, as described above, Silicon Valley accounts for almost $40 \%$ of the observations of outbound mobility and 35\% of the firms. In addition, Japan accounts also for almost 50\% of the total number of the cases of outbound mobility in the same region. For this reason, the effect of outbound mobility when contained in a geographic region has to be taken with caution because it may just reflect idiosyncrasies of these two regions. On the other hand, Silicon Valley and Japan together account only for $20 \%$ of the cases of outbound mobility across a region, which provides some reassurance about the generalizability of the results over distance. 
This study opens a series of questions that future research should address. First, what other knowledge transfer mechanisms are involved in industrial districts, their level of redundancy with each other, and the level of resilience this redundancy provides. Second, whether outbound mobility has different effects in particular regions; in other words, whether firms can benefit from outbound mobility inside some regions while other regions experience enough redundancy to make outbound mobility trivial. Finally, this study isolates the acquisition of knowledge through social capital from the acquisition through human capital. If these mechanisms are truly separable, the human capital mechanism would limit the transfer of knowledge to that which is developed before the employee moves, while the social capital mechanism implies that newer knowledge may still be transferred. Future research should examine these effects to further isolate them from alternative explanations by eliminating the possibility of confounding variables, such as the convergence of technological trajectories that facilitate the mobility of employees between firms.

\section{CONCLUSION}

This paper advances our understanding of the effect of mobility in the transfer of technological knowledge by conceptualizing the mobility of employees as an event that involves two different mechanisms: a) the transfer of knowledge and skills embedded in the individual moving between firms, and b) the development of new social ties between the firms. In addition, we were able to empirically isolate the mechanism of social tie creation from the one of human capital transfer by means of studying outbound mobility, and found a positive effect of the mobility of an employee on the knowledge transferred to the firm losing her; effect that diminishes when both firms are geographically proximate.

This study contributes to the literature on knowledge transfer by conceptualizing the effect of employee mobility as bidirectional, and recognizing and measuring the possible reverse transfer of knowledge. The migration of an employee has usually been associated with a negative effect on the firm: even laypersons' vocabulary referred to this migration as the loss of an employee. This outbound mobility has been seen as a loss of human capital, skills and organizational knowledge. In the best case scenario, this migration would not translate into a loss if the knowledge embedded in the employee was truly 
organizational or redundant. The work of Agrawal and colleagues (2003) shows that, at the regional level, there is a spillover from the region that receives the employee to the region that lost the employee. But it is a more precise step forward to associates the loss of and employee with a firm-level gain of skills or knowledge of any sort. Work in this area has typically found firm-level losses (Phillips 2002; Wezel, Cattani, and Pennings 2006), or, in one case, that firms were able to avert the negative consequences attributable to losing technical committee representatives to firm-level routines for personnel replaces and ongoing conferral of status (Dokko and Rosenkopf 2006). Our paper clearly highlights the importance of the mobility ties in the organizational learning process, even when employees leave the firm.

Finally, this work corroborates the importance of networks based on individual's ties on organizational level outcomes, and helps to better understand the mechanisms behind information transfer at the frontier of knowledge. This claim should not be construed as promoting outbound mobility but as pointing to the fact that, at least at low levels, mobility facilitates the transfer of knowledge between firms at the frontier of innovation in both directions, and that there are ways for the firm experiencing outbound mobility to obtain benefits from these events.

\section{REFERENCES}

Agrawal, Ajay. 2001. University-to-industry Knowledge Transfer: Literature Review and Unanswered Questions. In International Journal of Management Reviews: Blackwell Publishing Limited. Agrawal, Ajay, Iain Cockburn, and John McHale. 2003. Gone but not Forgotten: Knowledge Flows, Labor Mobility, and Enduring Social Relationships. In NBER Working Paper.

Allen, Thomas J. 1970. Communication Networks in R\&D Laboratories. R\&D Management 1 (1):14-21.

-1977. Managing the flow of technology : technology transfer and the dissemination of technological information within the R\&D organization. Cambridge, Mass.: MIT Press.

Allison, Paul D. 1999. Logistic regression using the SAS system : theory and application. Cary, N.C.: SAS Institute.

Almeida, Paul , Gina Dokko, and Lori Rosenkopf. 2003. Startup size and the mechanisms of external learning: increasing opportunity and decreasing ability? Research Policy 32 (2):301-315. 
Almeida, Paul , Jaeyong Song, and Robert M. Grant. 2002. Are Firms Superior to Alliances and Markets? An Empirical Test of Cross-Border Knowledge Building. Organization Science: A Journal of the Institute of Management Sciences 13 (2):147.

Almeida, Paul, and Bruce Kogut. 1997. The exploration of technological diversity and the geographic localization of innovation. Small Business Economics 9 (1):21-31.

- 1999. Localization of Knowledge and the Mobility of Engineers in Regional Networks. Management Science 45 (7):905-917.

Argote, L., P. Ingram, J. M. Levine, and R. L. Moreland. 2000. Knowledge transfer in organizations: Learning from the experience of others. Organizational Behavior and Human Decision Processes $82(1): 1-8$.

Boeker, Warren. 1997. Executive Migration and Strategic Change: The Effect of Top Manager Movement on Product-Market Entry. Administrative Science Quarterly 42 (2):213-236.

Bui-Eve, H. 1997. To hire or not to hire: What silicon valley companies should know about hiring competitors' employees. Hastings Law Journal 48 (5):981-+.

Burt, Ronald S. 1992. Structural holes : the social structure of competition. Cambridge, Mass.: Harvard University Press.

Cameron, Adrian C., and Pravin K. Trivedi. 1998. Regression analysis of count data, Econometric society monographs ; no. 30. Cambridge, UK ; New York, NY, USA: Cambridge University Press.

Cohen, Michael D., Richard R. Nelson, and John P. Walsh. 2000. Protecting Their Intellectual Assets: Appropriability Conditions and Why U.S. Manufacturing Firms Patent (or Not). In NBER WORKING PAPER SERIES.

Cohen, Wesley M., Akira Goto, Akiya Nagata, Richard R. Nelson, and John P. Walsh. 2002. R\&D spillovers, patents and the incentives to innovate in Japan and the United States. Research Policy $31(8-9): 1349-1367$.

Cohen, Wesley M., and Daniel A. Levinthal. 1990. Absorptive Capacity: A New Perspective On Learning And Innovation. Administrative Science Quarterly 35 (1):128. 
DeCarolis, Donna M., and David L. Deeds. 1999. The impact of stocks and flows of organizational knowledge on firm performance: an empirical investigation of the biotechnology industry. Strategic Management Journal 20 (10):953-968.

DiMaggio, Paul J., and Walter W. Powell. 1983. The Iron Cage Revisited: Institutional Isomorphism and Collective Rationality in Organizational Fields. American Sociological Review 48 (2):147-160.

Dokko, Gina, and Lori Rosenkopf. 2006. Social Capital for Hire? Mobility of Technical Professionals and Firm Influence in Wireless Standards Committees. In Working Paper.

Fleming, Lee, Lyra Colfer, Alexandra Marin, and Jonathan McPhie. 2004. Why the Valley Went First: Agglomeration and Emergence in Regional Inventor Networks.

Granovetter, Mark. 1985. Economic Action and Social Structure: The Problem of Embeddedness. American Journal of Sociology 91 (3):481-510.

Hagerstrand, Torsten. 1967. Innovation diffusion as a spatial process. Chicago: University of Chicago Press.

Hall, Bronwyn H., Adam B. Jaffe, and Manuel Tratjenberg. 2001. The NBER Patent Citation Data File: Lessons, Insights and Methodological Tools. In NBER Working Paper.

Inkpen, Andrew C., and Eric W. K. Tsang. 2005. Social Capital, Networks, and Knowledge Transfer. In Academy of Management Review: Academy of Management.

Jaffe, Adam B. 1986. Technological Opportunity and Spillovers of R \& D: Evidence from Firms' Patents, Profits, and Market Value. The American Economic Review 76 (5):984-1001.

_ 1989. Characterizing the "technological position" of firms, with application to quantifying technological opportunity and research spillovers. Research Policy 18 (2):87-97.

Jaffe, Adam B., Manuel Trajtenberg, and Rebecca Henderson. 1993. Geographic localization of knowledge spillovers as evidenced by patent citations. Quarterly Journal of Economics 108 (3):577.

Jung, Carl G., and Marie-Luise von Franz, eds. 1968. Man and his symbols. New York: Dell. 
Levin, Richard C. 1988. Appropriability, R\&D Spending, and Technological Performance. The American Economic Review 78 (2, Papers and Proceedings of the One-Hundredth Annual Meeting of the American Economic Association):424-428.

Mantel, Nathan, and William Haenszel. 1959. Statistical Aspects of the Analysis of Data from Retrospective Studies of Disease. Journal of the National Cancer Institute 22 (719-748).

Marquis, Donald G., and Thomas J. Allen. 1966. Communication Patterns in Applied Technology. American Psychologist 21:1052-1060.

Merton, Robert K. 1973. The sociology of science : theoretical and empirical investigations. Chicago: University of Chicago Press.

Mowery, David C., Joanne E. Oxley, and Brian S. Silverman. 1998. Technological overlap and interfirm cooperation: implications for the resource-based view of the firm. Research Policy 27 (5):507523.

Nelson, Richard R., and Sidney G. Winter. 1982. An evolutionary theory of economic change. Cambridge, Mass.: Belknap Press of Harvard University Press.

Ocasio, William. 1997. Towards an Attention-Based View of the Firm. Strategic Management Journal 18 (Summer 1997 Special Issue: Organizational and Competitive Interactions):187-206.

Phillips, Damon J. 2002. A genealogical approach to organizational life chances: The parent-progeny transfer among Silicon Valley law firms, 1946-1996. Administrative Science Quarterly 47 (3):474.

Price, Derek J. de Solla. 1986. Little science, big science-- and beyond. New York: Columbia University Press.

Rao, Hayagreeva, and Robert Drazin. 2002. Overcoming Resource Constraints on Product Innovation by Recruiting Talent From Rivals: A Study of the Mutual Fund Industry, 1986-94. Academy of Management Journal 45 (3):491-507.

Rogers, Everett M. 2003. Diffusion of innovations. 5th ed. New York: Free Press. 
Rogers, Everett M., and Judith K. Larsen. 1984. Silicon Valley fever : growth of high-technology culture. New York: Basic Books.

Rosenkopf, Lori, and Paul Almeida. 2003. Overcoming Local Search Through Alliances and Mobility. Management Science 49 (6):751-766.

Saxenian, AnnaLee. 1994. Regional advantage : culture and competition in Silicon Valley and Route 128. Cambridge, Mass.: Harvard University Press.

Singh, Jasjit. 2003. Inventor Networks and Inter-Firm Knowledge Diffusion. In Harvard Business School. Song, Jaeyong, Paul Almeida, and Geraldine Wu. 2003. Learning-by-Hiring: When Is Mobility More Likely to Facilitate Interfirm Knowledge Transfer? Management Science 49 (4):351-365.

Stuart, Toby E. 2000. Interorganizational alliances and the performance of firms: A study of growth and innovation rates in a high-technology industry. Strategic Management Journal 21 (8):791-811.

Stuart, Toby E., and Joel M. Podolny. 1996. Local Search and the Evolution of Technological Capabilities. Strategic Management Journal 17 (Special Issue: Evolutionary Perspectives on Strategy):21-38.

von Hippel, Eric. 1987. Cooperation between rivals: Informal know-how trading. Research Policy 16 (6):291-302.

Wezel, Filippo C., Gino Cattani, and Johannes M. Pennings. 2006. Competitive Implications of InterFirm Mobility. In Working Paper. 
Table 1. Metropolitan Statistical Areas (MSA) Where Semiconductor Firms Are Located

(Metropolitan areas defined by Office of Management and Budget, 6/30/93)

\begin{tabular}{|c|c|c|}
\hline $\begin{array}{c}\text { MSA } \\
\text { CODE or } \\
\text { COUNTRY }\end{array}$ & Metropolitan Area or Country Names & $\begin{array}{l}\text { Number } \\
\text { of Firms }\end{array}$ \\
\hline 7362 & San Francisco-Oakland-San Jose, CA & 56 \\
\hline 4472 & Los Angeles-Riverside-Orange County, CA & 9 \\
\hline 5602 & New York-Northern New Jersey-Long Island, NY-NJ-CT-PA & 7 \\
\hline 1122 & Boston-Worcester-Lawrence, MA-NH-ME-CT & 4 \\
\hline 1922 & Dallas-Fort Worth, TX & 4 \\
\hline 6442 & Portland-Salem, OR-WA & 4 \\
\hline 1692 & Cleveland-Akron, $\mathrm{OH}$ & 2 \\
\hline 2162 & Detroit-Ann Arbor-Flint, MI & 2 \\
\hline 5120 & Minneapolis-St. Paul, MN-WI & 2 \\
\hline 6162 & Philadelphia-Wilmington-Atlantic City, PA-NJ-DE-MD & 2 \\
\hline 7320 & San Diego, CA & 2 \\
\hline 1080 & Boise City, ID & 1 \\
\hline 1602 & Chicago-Gary-Kenosha, IL-IN-WI & 1 \\
\hline 1720 & Colorado Springs, CO & 1 \\
\hline 3280 & Hartford, CT & 1 \\
\hline 3362 & Houston-Galveston-Brazoria, TX & 1 \\
\hline 4992 & Miami-Fort Lauderdale, FL & 1 \\
\hline 6200 & Phoenix-Mesa, AZ & 1 \\
\hline 6280 & Pittsburgh, PA & 1 \\
\hline 6340 & Pocatello, ID & 1 \\
\hline 6480 & Providence-Fall River-Warwick, RI-MA & 1 \\
\hline 6640 & Raleigh-Durham-Chapel Hill, NC & 1 \\
\hline 8520 & Tucson, AZ & 1 \\
\hline US & *Not in a MSA* & 3 \\
\hline JP & Japan & 23 \\
\hline TW & Taiwan & 6 \\
\hline $\mathrm{CA}$ & Canada & 3 \\
\hline KR & Korea & 3 \\
\hline $\mathrm{DE}$ & Denmark & 2 \\
\hline FR & France & 2 \\
\hline GB & Great Britain & 2 \\
\hline IN & India & 1 \\
\hline IT & Italy & 1 \\
\hline SE & Sweden & 1 \\
\hline SG & Singapore & 1 \\
\hline
\end{tabular}

NOTE: MSA names reflect the major cities in the area. As an example, Silicon Valley is located in MSA 7362 (San Francisco-Oakland-San Jose, CA). Components for each area (counties and towns) can be found at: http://www.census.gov/population/estimates/metro-city/93mfips.txt 
Figure 1. Distribution of mobility and alliance events (1980-1994)

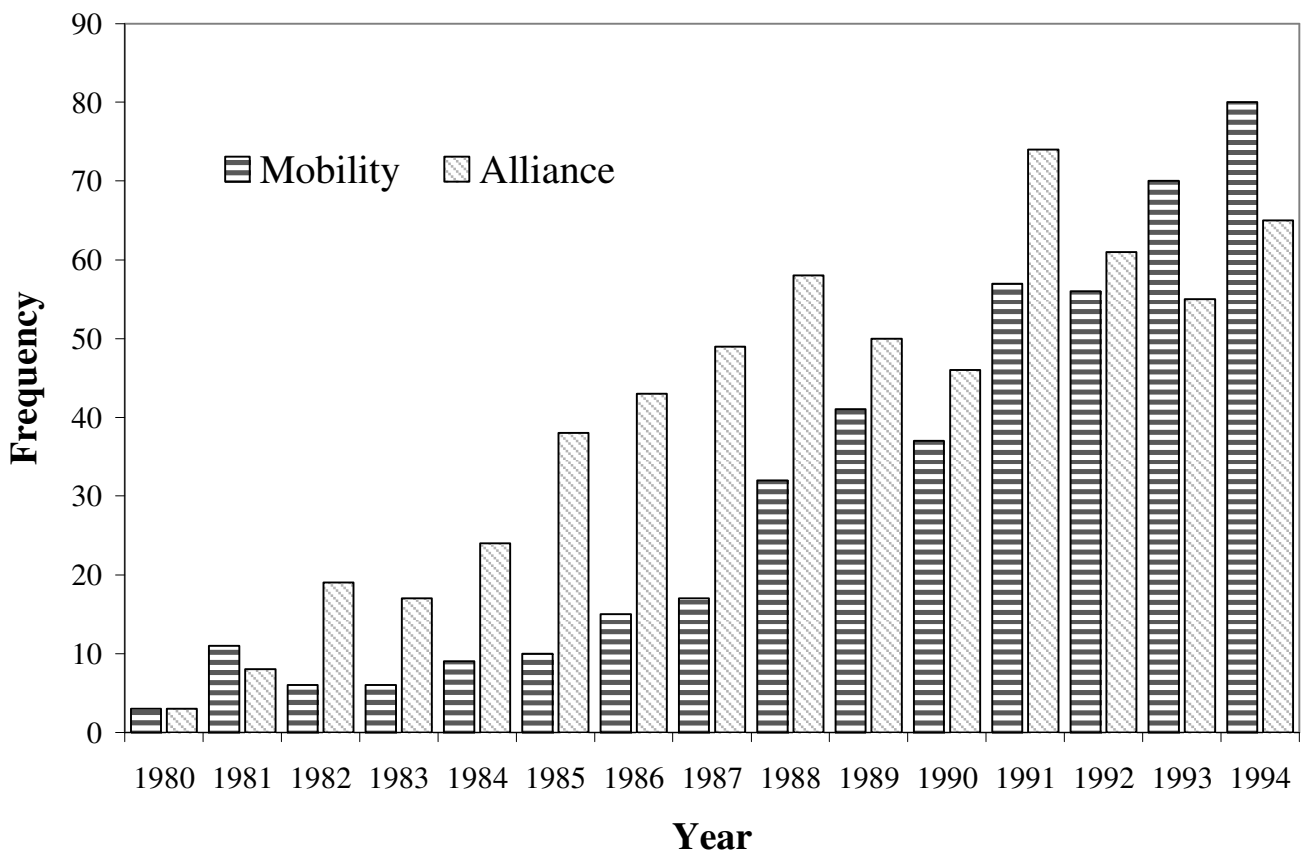

Table 2. Observations for Outbound Mobility (OutMob), Hiring and Alliance per focal firm's Region and Geographic Proximity between firms

\begin{tabular}{|c|c|c|c|c|c|}
\hline \multicolumn{2}{|c|}{ Geographic Proximity } & Outmob & Hiring & Alliance & Obs \\
\hline \multicolumn{2}{|l|}{1} & 549 & 549 & 419 & 21266 \\
\hline \multicolumn{2}{|l|}{$\mathbf{0}$} & 683 & 683 & 2517 & 119348 \\
\hline \multicolumn{2}{|l|}{$\chi 2$-tests ${ }^{\dagger}$} & $<.00001$ & $<.00002$ & 0.19 & \\
\hline \multicolumn{6}{|c|}{ Test for Interdependence with Geographic Proximity } \\
\hline \multicolumn{6}{|l|}{$2 b$} \\
\hline Region & $\begin{array}{l}\text { Geographic } \\
\text { Proximity }\end{array}$ & $\begin{array}{c}\text { Outbound } \\
\text { Mobility }\end{array}$ & Hiring & Alliance & Obs \\
\hline \multirow{2}{*}{ Silicon Valley } & 1 & 186 & 186 & 239 & 15753 \\
\hline & 0 & 81 & 175 & 630 & 31400 \\
\hline \multirow{2}{*}{ Japan } & 1 & 299 & 299 & 134 & 4294 \\
\hline & 0 & 71 & 72 & 608 & 21756 \\
\hline \multirow{2}{*}{ Los Angeles } & 1 & 25 & 25 & 8 & 464 \\
\hline & 0 & 64 & 12 & 144 & 8179 \\
\hline \multirow{2}{*}{ New York } & 1 & 14 & 14 & 0 & 240 \\
\hline & 0 & 92 & 58 & 207 & 6089 \\
\hline \multirow{2}{*}{ Other Regions } & 1 & 25 & 25 & 38 & 515 \\
\hline & 0 & 375 & 366 & 928 & 51924 \\
\hline Total & & 1232 & 1232 & 2936 & 140614 \\
\hline
\end{tabular}


Table 3. Correlation Matrix and Descriptive Statistics.

\begin{tabular}{|c|c|c|c|c|c|c|c|c|c|c|}
\hline & Cites & Outmob & Hiring & Alliance & TechDist & GeoProx & $\begin{array}{l}\text { Log } \\
\text { (FocPat) }\end{array}$ & $\begin{array}{l}\text { Log } \\
\text { (FocPat5) }\end{array}$ & $\begin{array}{l}\text { Log } \\
\text { (AltPat10) }\end{array}$ & $\begin{array}{c}\text { Outmob } \\
* \\
\text { GeoProx } \\
\end{array}$ \\
\hline Cites & 1 & 0.121 & 0.130 & 0.139 & -0.216 & 0.001 & 0.298 & 0.274 & 0.247 & 0.080 \\
\hline Outmob & 0.121 & 1 & 0.178 & 0.088 & -0.077 & 0.077 & 0.126 & 0.141 & 0.098 & 0.666 \\
\hline Hiring & 0.130 & 0.178 & 1 & 0.088 & -0.077 & 0.077 & 0.103 & 0.102 & 0.142 & 0.175 \\
\hline Alliance & 0.139 & 0.088 & 0.088 & 1 & -0.095 & -0.003 & 0.138 & 0.141 & 0.139 & 0.057 \\
\hline TechDist & -0.216 & -0.077 & -0.077 & -0.095 & 1 & 0.100 & -0.234 & -0.224 & -0.226 & -0.048 \\
\hline GeoProx & 0.001 & 0.077 & 0.077 & -0.003 & 0.100 & 1 & -0.053 & -0.057 & -0.063 & 0.148 \\
\hline Log(FocPat) & 0.298 & 0.126 & 0.103 & 0.138 & -0.234 & -0.053 & 1 & 0.927 & 0.003 & 0.085 \\
\hline $\log ($ FocPat5) & 0.274 & 0.141 & 0.102 & 0.141 & -0.224 & -0.057 & 0.927 & 1 & 0.006 & 0.092 \\
\hline Log(AltPat10) & 0.247 & 0.098 & 0.142 & 0.139 & -0.226 & -0.063 & 0.003 & 0.006 & 1 & 0.070 \\
\hline Outmob*GeoProx & 0.080 & 0.666 & 0.175 & 0.057 & -0.048 & 0.148 & 0.085 & 0.092 & 0.070 & 1 \\
\hline MEAN & 0.232 & 0.009 & 0.009 & 0.021 & 0.490 & 0.151 & 13.665 & 45.747 & 67.262 & 0.004 \\
\hline STD & 0.909 & 0.093 & 0.093 & 0.143 & 0.451 & 0.358 & 29.446 & 105.256 & 154.436 & 0.062 \\
\hline $\mathbf{N}$ & 140614 & 140614 & 140614 & 140614 & 140614 & 140614 & 140614 & 140614 & 140614 & 140614 \\
\hline
\end{tabular}

NOTE: All Pearson correlations are significant at $p$-value $<0.001$

Table 4. Frequency counts for Cites for the period 1985-1995

\begin{tabular}{rrrrr}
\hline Cites & Frequency & Percent & $\begin{array}{c}\text { Cumulative } \\
\text { Frequency }\end{array}$ & $\begin{array}{c}\text { Cumulative } \\
\text { Percent }\end{array}$ \\
\hline 0 & 126098 & 89.68 & 126098 & 89.68 \\
1 & 7558 & 5.37 & 133656 & 95.05 \\
2 & 2838 & 2.02 & 136494 & 97.07 \\
3 & 1429 & 1.02 & 137923 & 98.09 \\
4 & 885 & 0.63 & 138808 & 98.72 \\
5 & 598 & 0.43 & 139406 & 99.14 \\
6 & 452 & 0.32 & 139858 & 99.46 \\
7 & 322 & 0.23 & 140180 & 99.69 \\
8 & 254 & 0.18 & 140434 & 99.87 \\
9 & 180 & 0.13 & 140614 & 100 \\
\hline
\end{tabular}


Table 5. Zero-Inflated Negative Binomial Regression Models with Fixed Effects on Focal Firm.

\begin{tabular}{|c|c|c|c|c|c|c|c|c|c|c|}
\hline \multirow{3}{*}{$\begin{array}{l}\text { Model } \\
\text { PARAMETER }\end{array}$} & \multirow{2}{*}{\multicolumn{2}{|c|}{$\mathbf{A}$}} & \multirow{2}{*}{\multicolumn{2}{|c|}{ B }} & \multirow{2}{*}{\multicolumn{2}{|c|}{$\mathbf{C}$}} & \multirow{2}{*}{\multicolumn{2}{|c|}{ D }} & \multirow{2}{*}{\multicolumn{2}{|c|}{$\mathbf{E}$}} \\
\hline & & & & & & & & & & \\
\hline & \multicolumn{2}{|c|}{ Estimate } & \multicolumn{2}{|c|}{ Estimate } & \multicolumn{2}{|c|}{ Estimate } & \multicolumn{2}{|c|}{ Estimate } & \multicolumn{2}{|c|}{ Estimate } \\
\hline b0_prob & 3.660 & & 3.634 & * & 3.545 & & 3.643 & ** & 3.671 & \\
\hline & $(3.848)$ & & $(2.023)$ & & $(9.582)$ & & $(1.778)$ & & $(2.860)$ & \\
\hline bTechDist_prob & 0.486 & $* \star *$ & 0.536 & $\star \star \star *$ & 0.548 & $* * *$ & 0.522 & $\star \star \star *$ & 0.460 & *** \\
\hline & $(0.146)$ & & $(0.143)$ & & $(0.160)$ & & $(0.145)$ & & $(0.145)$ & \\
\hline bLogFocPat_prob & -0.200 & $* * *$ & -0.205 & $* \star *$ & -0.203 & $* * *$ & -0.205 & $* * *$ & -0.200 & $* * *$ \\
\hline & $(0.016)$ & & $(0.016)$ & & $(0.016)$ & & $(0.016)$ & & $(0.016)$ & \\
\hline bLogAltPat10_prob & -0.555 & $* * *$ & -0.554 & $* * *$ & -0.550 & $* * *$ & -0.553 & $* \star *$ & -0.555 & $* * *$ \\
\hline & $(0.015)$ & & $(0.014)$ & & $(0.015)$ & & $(0.015)$ & & $(0.015)$ & \\
\hline \multicolumn{11}{|l|}{ Negative Binomial } \\
\hline yr86_nb & 0.074 & & 0.078 & & 0.076 & & 0.072 & & 0.073 & \\
\hline & $(0.061)$ & & $(0.061)$ & & $(0.061)$ & & $(0.061)$ & & $(0.061)$ & \\
\hline yr87_nb & 0.100 & * & 0.102 & * & 0.101 & * & 0.098 & * & 0.100 & * \\
\hline & $(0.058)$ & & $(0.058)$ & & $(0.058)$ & & $(0.058)$ & & $(0.058)$ & \\
\hline yr88_nb & 0.218 & $* * *$ & 0.218 & $\star \star \star *$ & 0.221 & $* \star *$ & 0.217 & $* * *$ & 0.220 & $* * *$ \\
\hline & $(0.057)$ & & $(0.057)$ & & $(0.057)$ & & $(0.057)$ & & $(0.057)$ & \\
\hline yr89_nb & 0.175 & $* * *$ & 0.176 & $* * *$ & 0.182 & $* * *$ & 0.173 & $* * *$ & 0.177 & $* * *$ \\
\hline & $(0.056)$ & & $(0.056)$ & & $(0.055)$ & & $(0.056)$ & & $(0.055)$ & \\
\hline yr90_nb & 0.110 & ** & 0.109 & ** & 0.120 & ** & 0.108 & ** & 0.110 & ** \\
\hline & $(0.055)$ & & $(0.055)$ & & $(0.055)$ & & $(0.055)$ & & $(0.055)$ & \\
\hline yr91_nb & 0.115 & ** & 0.112 & ** & 0.120 & $\star *$ & 0.113 & ** & 0.115 & ** \\
\hline & $(0.054)$ & & $(0.054)$ & & $(0.054)$ & & $(0.054)$ & & $(0.054)$ & \\
\hline yr92_nb & 0.022 & & 0.018 & & 0.034 & & 0.021 & & 0.023 & \\
\hline & $(0.055)$ & & $(0.055)$ & & $(0.055)$ & & $(0.055)$ & & $(0.055)$ & \\
\hline yr93_nb & 0.035 & & 0.029 & & 0.039 & & 0.029 & & 0.030 & \\
\hline & $(0.056)$ & & $(0.056)$ & & $(0.056)$ & & $(0.056)$ & & $(0.056)$ & \\
\hline yr94_nb & 0.021 & & 0.013 & & 0.028 & & 0.015 & & 0.018 & \\
\hline & $(0.057)$ & & $(0.057)$ & & $(0.057)$ & & $(0.057)$ & & $(0.057)$ & \\
\hline yr95_nb & 0.484 & *** & 0.473 & $* * *$ & 0.506 & $\star * \star$ & 0.494 & $* * *$ & 0.504 & $* \star *$ \\
\hline & $(0.063)$ & & $(0.063)$ & & $(0.065)$ & & $(0.063)$ & & $(0.063)$ & \\
\hline b0_nb & -3.576 & & -3.685 & ** & -3.585 & & -3.780 & $* * *$ & -3.652 & \\
\hline & $(3.157)$ & & (1.657) & & $(7.945)$ & & (1.459) & & $(2.348)$ & \\
\hline bLogFocPat 5 & 0.080 & $* * *$ & 0.079 & $* * *$ & 0.079 & $* * *$ & 0.081 & $* * *$ & 0.082 & $* * *$ \\
\hline & $(0.013)$ & & $(0.013)$ & & $(0.014)$ & & $(0.013)$ & & $(0.013)$ & \\
\hline bLogAltPat 10 & 0.242 & $\star \star *$ & 0.242 & $* * *$ & 0.251 & $\star \star \star$ & 0.250 & $\star \star \star$ & 0.249 & $\star \star *$ \\
\hline & $(0.010)$ & & $(0.010)$ & & $(0.010)$ & & $(0.010)$ & & $(0.010)$ & \\
\hline bTechDist & 0.161 & & 0.201 & * & 0.243 & * & 0.230 & * & 0.187 & \\
\hline & $(0.118)$ & & $(0.116)$ & & $(0.133)$ & & $(0.117)$ & & $(0.118)$ & \\
\hline bAlliance & 0.129 & $\star * *$ & 0.126 & $* \star \star$ & 0.140 & $\star \star \star *$ & 0.139 & $* * *$ & 0.140 & $\star * *$ \\
\hline & $(0.032)$ & & $(0.032)$ & & $(0.032)$ & & $(0.032)$ & & $(0.032)$ & \\
\hline bHire & 0.130 & $* * *$ & 0.109 & $* * *$ & 0.035 & & 0.025 & & 0.032 & \\
\hline & $(0.042)$ & & $(0.042)$ & & $(0.042)$ & & $(0.043)$ & & $(0.043)$ & \\
\hline bOutMobility & & & 0.163 & $\star \star \star *$ & & & 0.074 & * & 0.198 & $* * *$ \\
\hline & & & $(0.044)$ & & & & $(0.044)$ & & $(0.057)$ & \\
\hline bProx & & & & & 0.313 & $* * *$ & 0.305 & $* * *$ & 0.331 & $* * *$ \\
\hline & & & & & $(0.027)$ & & $(0.028)$ & & $(0.029)$ & \\
\hline bOutMob_Prox & & & & & & & & & -0.306 & $* * *$ \\
\hline & & & & & & & & & $(0.088)$ & \\
\hline -2 Log Likelihood & 100891 & & 100874 & & 100766 & & 100753 & & 100743 & \\
\hline LR (p-value) ${ }^{\dagger}$ & & & $<.0001$ & & $<.0001$ & & 0.0003 & & 0.0016 & \\
\hline
\end{tabular}

Standard Errors in parentheses

†Tests for Ho that full model and reduced models are equivalent

$*$ p-value $<0.1 \quad * *$-value $<0.05 \quad * * * p$-value $<0.01$ 